\section{Nature of Free Iron Oxides in Soil Clays}

A DIFFERENTIAL thermal analysis examination of soil clays at present in progress with the view of elucidating their mineral composition has provided some evidence regarding the nature of the iron oxide coatings on the clay micelles. One of the clays studied, which had a free iron oxide content of 31 per cent, had been separated from a $C$-horizon sample (depth 48-52 in.) of a soil developed on basic igneous till and had been treated several times with hydrogen peroxide on the steam-bath to remove organic matter. Its thermogram shows a strong exothermic peak at about $345^{\circ} \mathrm{C}$. (curve $l$ in the graph), which because of its sharp well-defined nature appears to be quite different from the broad, rather diffuse band usually associated with organic matter, but which bears a considerable resemblance to that quoted by Berg, Nikolaiev and Rode ${ }^{1}$ for 'cold-precipitated' or 'glowing' hydrated ferric oxide ${ }^{2}$.

The similarity of the curves may be readily observed in the graph, where curve 2 is that obtained for 'cold-precipitated' hydrated ferric oxide in this laboratory. The oxide was precipitated from a ferric chloride solution by addition of excess $1: 1$ ammonia at room temperature (about $18^{\circ} \mathrm{C}$.), washed free from chloride and dried at $105^{\circ} \mathrm{C}$. in the oven. Material dried over phosphorus pentoxide in vacuo gives an identical curve. Repeated treatment of the oxide with hydrogen peroxide on the steam-bath-the normal procedure for removing organic matter from soil clays-does not affect the curve appreciably (curve 3). In connexion with the formation of these



Differential thermal analysis curves.

1 , Soil clay, No. $15260 ; 2$, hydrated ferric oxide precipitated at $18^{\circ} \mathrm{C}$; 3, 'cold-precipitated' hydrated ferric oxide treated six times with hydrogen peroxide ; 4 , hydrated ferric oxide precipit. ated at $100^{\circ} \mathrm{C}$.; 5 , soil clay No. 4734? ferric oxide gels, it is notew orthy that the temperature of precipitation affects the curve very appreciably; for example, precipitation at $100^{\circ} \mathrm{C}$. displaces the exothermic peak to $503^{\circ} \mathrm{C}$. (curve 4), whereas pre. cipitation at temperatures between $18^{\circ}$ and $100^{\circ} \mathrm{C}$. causes the peak to appear at temperatures between $345^{\circ} \mathrm{C}$. and $503^{\circ} \mathrm{C}$. In view of these facts it would seem that the 'cold-precipitated' hydrated ferric oxide occurs as such in the soil and is not formed by any pretreatment, for example, by precipitation dur. ing the decomposition of organo-metallic complexes by hydrogen peroxide.

Several other soil clays have since been found to contain this type of ferric oxide, but generally in smaller amounts (cf. curve 5). A survey of the literature reveals that somewhat similar small peaks have frequently been observed on thermograms of soil clays; but they apparently have been interpreted as organic matter incompletely removed. However, the sharpness of the peaks and the constancy of the peak temperature, as well as their occurrence on thermograms of clays from lower horizons of the profile which have been well peroxidized to remove organic matter, seem to exclude this possibility.

Goethite, which gives a strong endothermic effect at $380^{\circ} \mathrm{C}$., has been observed in only a few of the soil clays examined.

These iron oxide coatings normally show up only as a diffuse background on X-ray photographs of soil clays, and an electron diffraction examination of four soil clays shows no sign of crystallinity in the coating. It would, therefore, appear that differential thermal analysis is at present the only method of investigating them.

The differential thermal analysis apparatus employed in these investigations is somewhat similar to that described by Grimshaw, Heaton and Roberts ${ }^{3}$ : a ceramic specimen holder is used; exothermic peak temperatures are quoted as the temperature of the inert material at the peak; endothermic peak temperatures are corrected to the temperature of the sample at the peak; sample weights for soil clays are $0.2 \mathrm{gm}$., for iron oxides $0.35 \mathrm{gm}$.

Further work is in progress, especially with the view of elucidating the conditions of formation of these oxides in the soil, and a full report will be published elsewhere. I would like to thank Prof. G. I. Finch, of the Imperial College of Science and Technology, London, for supplying the electron diffraction data.

Macaulay Institute for Soil Research, Robert C. MackenzIE Craigiebuckler, Aberdeen. Feb. 15 .

1 “Thermographia", 85 (Acad. Sci. U.S.S.R., 1944).

2 See, for example, Fricke and Huttig, "Hydroxyde und Oxyhydrate", 335 (Leipzig, 1937).

${ }^{3}$ Trans. Brit. Ceram. Soc., 44, 69 (1945).

\section{Structure of Stearic Acid Films on Copper}

IN a recent communication ${ }^{1}$, Spink, using electron diffraction technique, postulates the presence of copper stearate after a copper surface covered with stearic acid has been heated. Two facts are quoted in support of this hypothesis. (1) When such a film is heated in the diffraction camera, the pattern finally fades at a temperature of $127-130^{\circ} \mathrm{C}$., that is, close to the softening point of copper stearate. This observation confirms that of Brummage ${ }^{2}$, and also 